\title{
10000 years later: evolution of body shape in Haida Gwaii three-spined stickleback
}

\author{
M. A. Spoljaric and T. E. Reimchen* \\ Department of Biology, University of Victoria, Victoria BC V8X 4A5, Canada
}

(Received 29 April 2006, Accepted 23 December 2006)

\begin{abstract}
The body shape of 1303 adult male three-spined stickleback Gasterosteus aculeatus from 118 populations on Haida Gwaii archipelago off the mid-coast of British Columbia was investigated using discriminant function analysis on partial warp scores generated from 12 homologous landmarks on a digital image of each fish. Results demonstrated geographical differences in adult body shape that could be predicted by both abiotic and biotic factors of the habitat. Populations with derived shape (CV1-), including thick peduncles, posterior and closely spaced dorsal spines, anterior pelvis, small dorsal and anal fins, were found in small, shallow, stained ponds, and populations with less derived shape $(\mathrm{CV} 1+)$, with small narrow peduncles, anterior and widely spaced dorsal spines, posterior pelvis, large dorsal and anal fins were found in large, deep, clear lakes. This relationship was replicated between geographic regions; divergent mtDNA haplotypes in lowland populations; between predation regimes throughout the archipelago, and in each geographical region and between predation regimes in lowland populations monomorphic for the Euro and North American mtDNA haplotype. There were large-bodied populations with derived shape (CV2-), including small heads and shallow elongate bodies in open water habitats of low productivity, and populations with smaller size and less derived shape (CV2+), with large heads and deeper bodies in higher productivity, structurally complex habitats. This relationship was replicated between geographic regions, and partially between divergent mtDNA haplotypes in lowland populations. Field tests for phenotypic plasticity of body shape suggest that $<10 \%$ of the total variation in body shape among populations throughout the archipelago can be attributed to plasticity. 2007 The Authors

Journal compilation $(2007$ The Fisheries Society of the British Isles
\end{abstract}

Key words: adaptation; Gasterosteus; geometric morphometrics; hydrodynamic landscape; phenotypic plasticity; Queen Charlotte Islands.

\section{INTRODUCTION}

Environmental heterogeneity in the selective landscape can lead to adaptive radiations with predictable evolutionary outcomes (Lack, 1947; Grant et al., 1976; Boag \& Grant, 1981; Grant \& Grant, 1995). Typically, adaptive radiations have been quantified through measurements of a few discrete trait characteristics (Lack, 1947; Williams, 1969, 1972; Grant et al., 1976; Losos, 1990). All traits, however, are related to the fitness of an organism and many may be

*Author to whom correspondence should be addressed. Tel.: +1 250721 7101; fax: +1 2507217120 ; email: reimchen@uvic.ca 
integrated (interactive response of multiple characters to specific selection regimes) (Schlichting, 1989; Bell \& Foster, 1994). Body shape reflects phenotypic integration as shape is often quantified by numerous correlated characters (Strauss \& Bookstein, 1982; Baumgartner et al., 1988; Rohlf, 1990; Bookstein, 1991; Baumgartner, 1992; Walker, 1997; Walker \& Bell, 2000; Klingenberg et al., 2003), which conserves shape during evolutionary diversification.

In aquatic organisms, drag reduction has been an important process in body shape evolution evident through the convergence of form in many diverse aquatic chordate groups (Aleev, 1977). Organisms differ in the niche space they occupy, and in aquatic species, the optimal body shape for ensuring survival is often correlated to physical and biological characteristics of the habitat (Walker, 1997; Guill et al., 2003a; Klingenberg et al., 2003; Langerhans et al., 2003; McGuigan et al., 2003). Variation in shape often reflects ecological and behavioural differences, which bear directly on traits important for fitness such as feeding efficiency, vulnerability to predators and reproductive success (Guill et al., 2003b; Klingenberg et al., 2003). In fishes, these traits have been linked directly to locomotor performance and efficiency, allowing organisms to occupy various habitats successfully (Swain, 1992; Guill et al., 2003a; McGuigan et al., 2003). Therefore, the body shape of fishes can be expected to be of particular ecological and evolutionary relevance (Klingenberg et al., 2003).

Locomotion and body shape are intrinsically linked, and shape can often be used to predict how a particular type of fish moves through the water (Webb, 1982; Sfakoitakis et al., 1999). Most often, fishes swim by lateral undulation of the body and tail fin, which can be used for both sustained and burst swimming (Breder, 1926; McGuigan et al., 2003). A streamlined body and a narrow caudal peduncle are characteristics of shape that confer maximum performance in sustained swimming, while a deep flexible body and deep caudal peduncle characterize shape adapted to maximize burst performance (Webb, 1982). Obviously, fishes with a body shape characteristic of sustained swimming can also use burst acceleration and vice versa. Shape adapted for maximum performance in one predominant mode of locomotion, however, can preclude maximum performance at the other (Reidy et al., 2000). Because of this trade-off, selection to increase sustained performance, for example, could result in streamlining of body shape which can lead to a proportionate decrease in burst performance (McGuigan et al., 2003).

Ecological interactions in different environments can have substantive effects on the evolution of body shape. Local environments provide the template on which evolution forges characteristic life-history strategies (Southwood, 1977; Townsend \& Hildrew, 1994). Following this premise, individuals from a single species in adjacent habitats can develop different morphologies in response to environmental cues, and these differences can often be attributed to phenotypic plasticity (Andersson, 2003). A genetic component to body shape, however, has been suggested (Walker, 1997; Guill et al., 2003a; Langerhans \& DeWitt, 2004) through the diversification of body shape in a few closely related fish species. The results from these investigations are consistent with principles of functional morphology, linking body shape to fitness through correlations with ecological factors of the habitat. 
One of the more striking examples of evolutionary radiation of vertebrates in the temperate latitudes are the isolated populations of three-spined stickleback Gasterosteus aculeatus L. from the Haida Gwaii archipelago (formerly known as the Queen Charlotte Islands), $100 \mathrm{~km}$ off the west coast of Canada. These populations of three-spined stickleback are ideal to study the evolution of body shape as many of the lakes, which are $c .10000$ years old, were each colonized by marine three-spined stickleback (trachurus) (Moodie \& Reimchen, 1976a). There is recent mitochondrial evidence that some of the lakes had two colonization events (O'Reilly et al., 1993; Orti et al., 1994; Deagle et al., 1996). The Haida Gwaii three-spined stickleback populations inhabit geographically isolated, relatively pristine lakes and streams, which encompass a wide range of abiotic and biotic variation (Moodie \& Reimchen, 1976a; Reimchen, 1994; Bergstrom \& Reimchen, 2002). This broad selective landscape has led to substantial diversification in three-spined stickleback among lakes including differences in maximum body size (30-115 mm standard length, $L_{\mathrm{S}}$ ) (Moodie, 1972a, $b$; Reimchen, 1991), nuptial colouration (Reimchen, 1989) and defensive morphology (Moodie \& Reimchen, 1976a; Reimchen et al., 1985). The differences among lake populations within this small area exceed that found throughout the rest of the circumboreal distribution including Alaska, eastern North America as well as northern Europe. The present study used geometric morphometrics to examine body shape variation among Haida Gwaii three-spined stickleback populations and assesses potential associations with biophysical variables of each habitat.

\section{MATERIALS AND METHODS}

\section{SAMPLING AND STUDY AREA}

Samples of three-spined stickleback from 99 lake, 19 stream and six marine localities on Haida Gwaii were collected from 1969 to 2003. These sites (Figs 1 and 2) encompass three major geographical zones (lowland, plateau and mountain). Three-spined stickleback were collected in the spring and summer using standard-mesh minnow traps baited with cheddar cheese and placed in the littoral zones (Reimchen et al., 1985; Reimchen, 1989, 1992a, 1994). Fish were fixed in 10\% formalin and stored in $95 \%$ ethanol. Six populations (two from streams and four from lakes) were excluded from the analysis of shape because there were no suitable male three-spined sticklebacks in the samples (i.e. shape compromised from previous investigations). Habitat biophysical data were also collected from a sub-set of localities during the fish collections $[\mathrm{pH}$, specific conductance, calcium concentration $(\mathrm{mmol})$, T400 (per cent $400 \mathrm{~nm}$ light transmission), lake area (ha), maximum depth $(\mathrm{m})$, volume $\left(\mathrm{m}^{3}\right)$, elevation $(\mathrm{m})$, distance to the ocean $(\mathrm{m})$ and predation regime (salmonid, bird and macroinvertebrate)].

\section{QUANTIFICATION OF BODY SHAPE}

Adult male three-spined stickleback $(n=1303)$ from 118 different populations on Haida Gwaii were photographed, and the digital images were used in the programme TPSDig (Rohlf, 2004) to produce data from 12 homologous landmarks (Fig. 3) (Bookstein, 1991) to quantify body shape. The programme TPSRegr (Rohlf, 2000) was used to align and scale the data in concordance with the generalized-least squares orthogonal Procrustes method, to generate partial warp scores (corresponding to variation in body shape at smaller scales), and the uniform component of shape change 


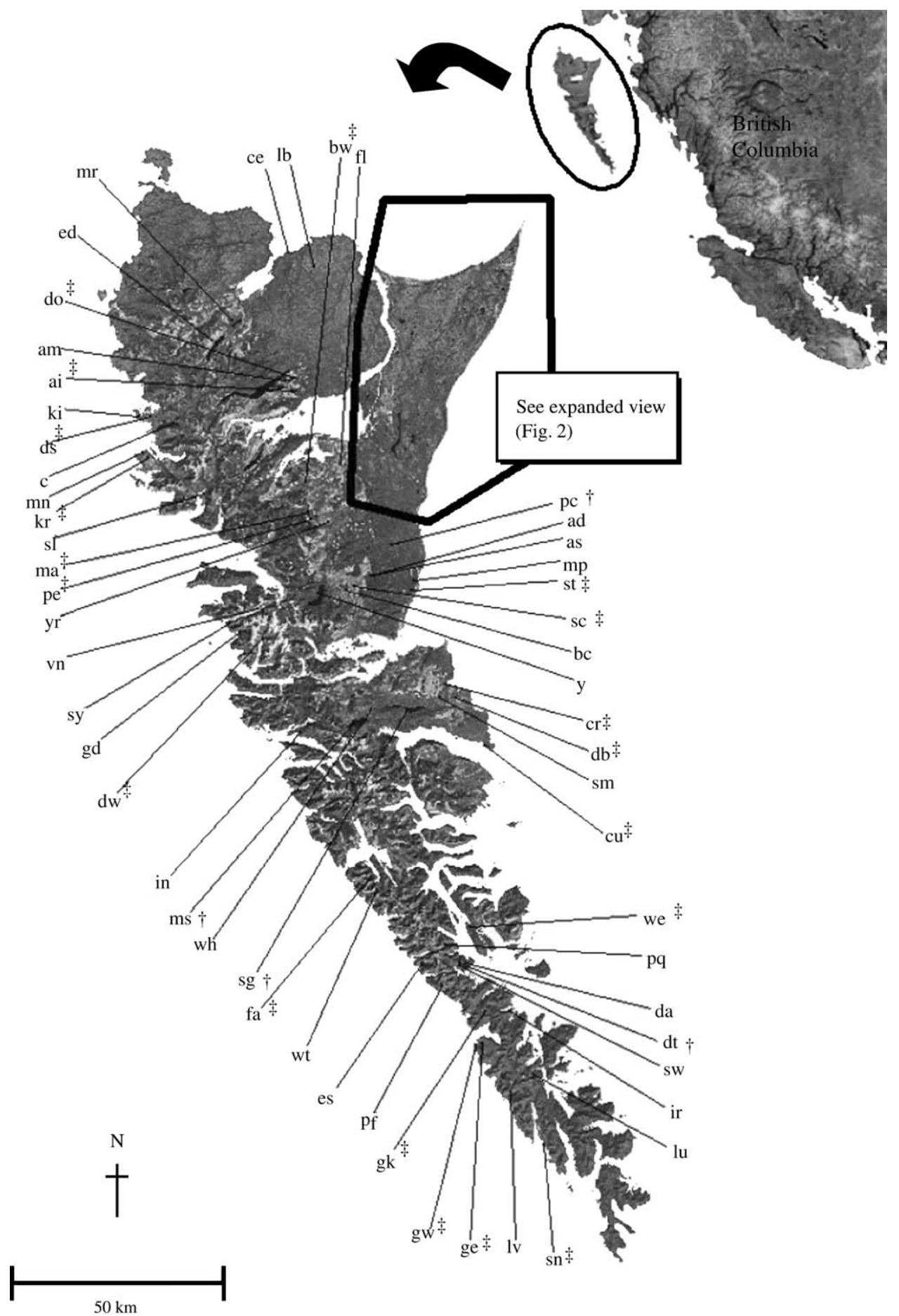

FIG. 1. Localities (see appendix) where three-spined stickleback were collected on Haida Gwaii. $\dagger$, Populations not used in the quantification of shape; $\ddagger$, populations with $n<10$. 


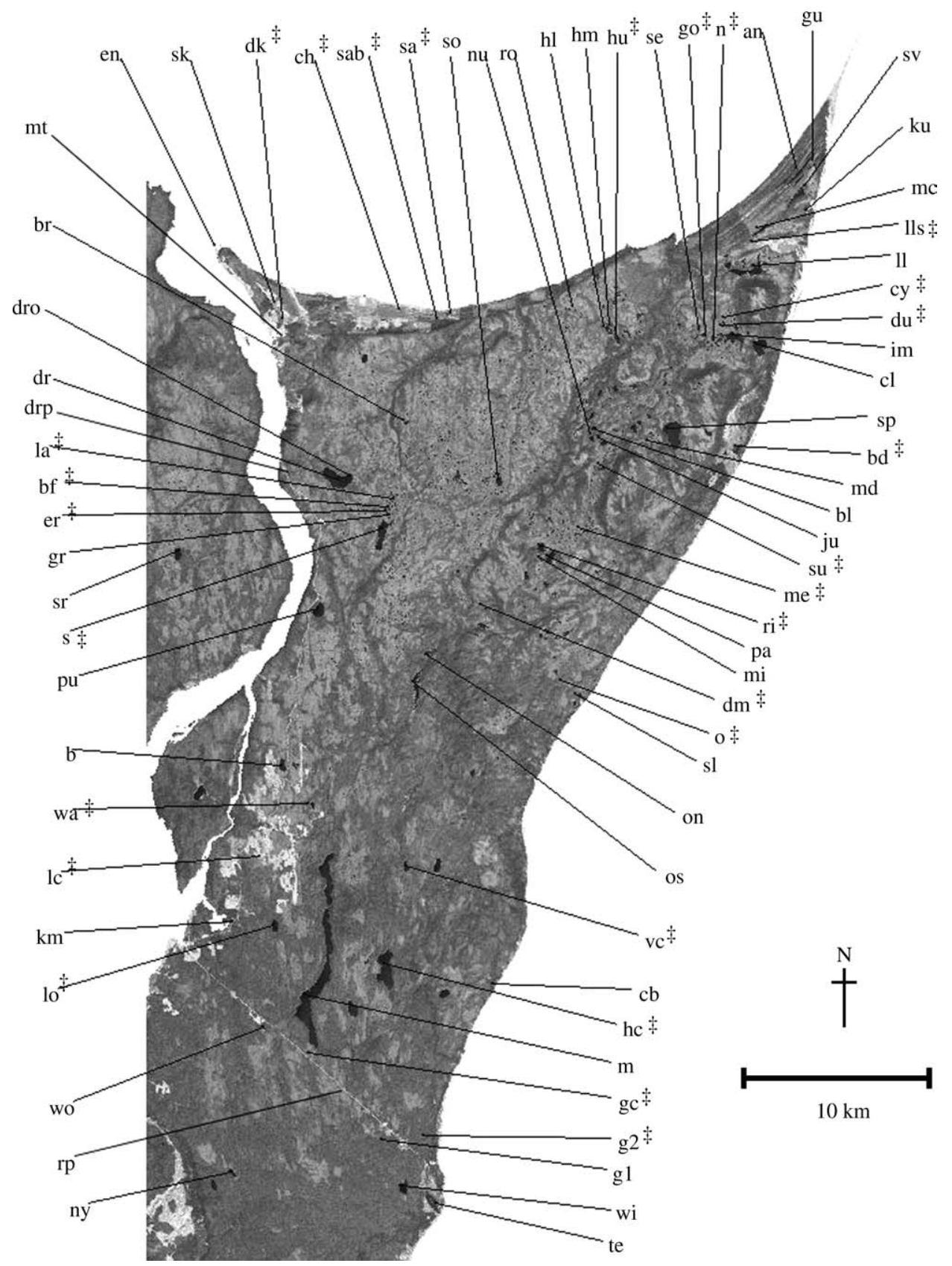

FIG. 2. Localities (see appendix) where three-spined stickleback were collected from the north-east corner of Haida Gwaii. $\uparrow$, Populations not used in the quantification of shape; $\$$, populations with $n<10$.

(large scale variation in shape from the alignment procedure; Rohlf, 1990, 1996, 1999). Discriminant function analysis was used on the partial warp and uniform component scores to predict group membership and quantify multivariate measures of body shape along canonical vectors (CVs), among specimens throughout the archipelago. The 


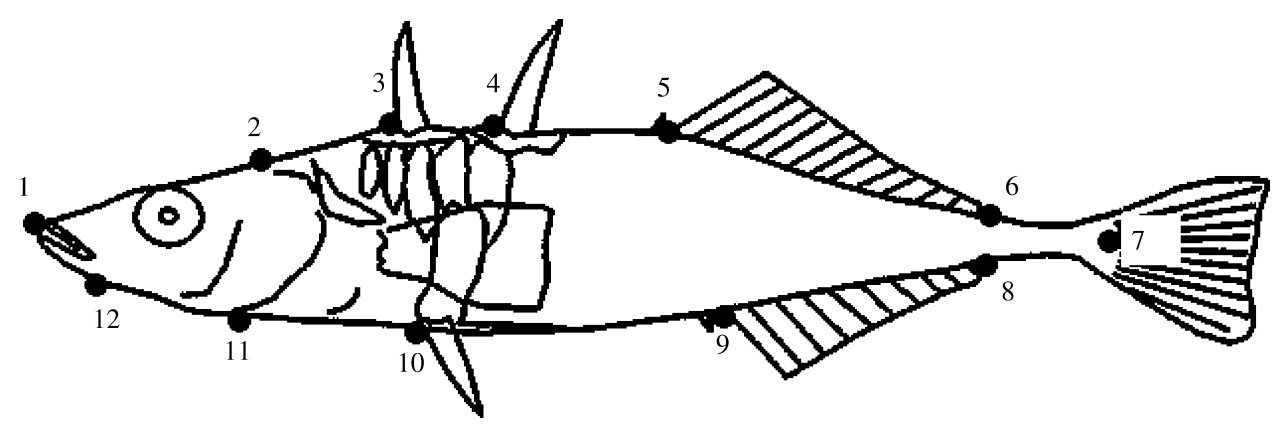

FIG. 3. Lateral view of three-spined stickleback showing the placement of landmarks used in the body shape analysis: 1, anterior tip of premaxilla; 2, supraoccipital notch immediately left of the dorsal midline (DML); 3, anterior junction of first dorsal spine and basal plate along the DML; 4, anterior junction of the second dorsal spine and basal plate along the DML; 5, base of the first dorsal fin ray at the DML; 6, insertion of the dorsal fin membrane on the DML; 7, caudal border of hypural plate at lateral midline; 8, insertion of anal fin membrane on ventral midline (VML); 9, base of first anal fin ray on VML; 10, posterior tip of ectocoracoid; 11, anterior border of ectocoracoid on VML; 12 , point of articulation between angular and quadrate.

uniform component was included to attain the total within population variation of body shape differences (Rohlf, 1993; Bookstein, 1996). Canonical vectors without the uniform component were tightly correlated to the $\mathrm{CV}$ scores used in the subsequent analysis (Pearson's correlation: CV1: $n=118, r=0 \cdot 98, P<0 \cdot 001$; CV2: $n=118$, $r=0.89, P<0 \cdot 001)$. Pearson correlation was used to describe body shape along each shape vector from log-linear regression transformed measurement (Reimchen et al., 1985) of standard morphometric variables.

To minimize ontogenetic effects and variation due to possible sexual shape dimorphism, the largest male three-spined stickleback from the samples were used for the shape analysis. Two analyses were performed: the first on all 118 populations regardless of male sample size ( $n$ ranges from 1 to 81), and the second on 72 samples which had $n \geq 10$ male three-spined stickleback. Although each of the test statistics differed between the two datasets, the statistically significant results were the same and therefore only the results for all 118 samples are reported. Univariate ANOVA was used to determine if there was any difference in body shape among populations. Population means for CV1 and CV2 were plotted against biophysical data to ascertain any ecological associations between body shape and habitat.

The configuration of landmarks for an individual specimen (i.e. the figure) has a mathematical centre (centroid). The size of a figure (centroid size) is the square root of the sums of squared distances of a set of landmarks from their centroid (Bookstein, 1991). Pearson's correlations between populations mean $\ln$ of centroid size and mean shape scores were used to determine if body shape quantified by canonical vectors was related to size.

\section{PHENOTYPIC PLASTICITY OF BODY SHAPE}

In 1992, a common garden experiment was started as part of the long-term investigation of three-spined stickleback from Haida Gwaii to investigate evolutionary responses to novel predation regimes and potential phenotypic plasticity. Giant melanistic three-spined stickleback from Mayer Lake, which is large (400 ha, maximum depth $10 \mathrm{~m}$ ) and dystrophic with high numbers of predatory fishes (Moodie, 1972b), were transplanted into a nearby small eutrophic pond $(0 \cdot 3$ ha and shallow maximum depth $1 \mathrm{~m}$ ), which lacked fishes. The biological and physical differences between Mayer Lake and the experimental pond are ecological opposites and span the range of habitat 
types on Haida Gwaii. A few years later, the experiment was replicated and giant melanistic three-spined stickleback from Drizzle Lake (97 ha with a maximum depth of $20 \mathrm{~m}$ ) were transplanted into another experimental pond $(0.5$ ha with a maximum depth of 1 $\mathrm{m})$. Again the source lake and recipient pond are ecological opposites (extreme limnetic niche $v$. extreme benthic niche) and provided an opportunity to assess the extent of phenotypic plasticity in body shape.

Tests for plasticity were conducted with several methods. Mean adult body shape of the source populations were compared to those of the first generation that had developed from eggs to adult in the experimental ponds. Shape comparisons of the experimental pond three-spined stickleback collected after 10 generations were compared with those of the source populations. In both instances, the same range of $L_{\mathrm{S}}$ of fish between the source and the experimental ponds were used. The per cent differences in population mean $\mathrm{CV}$ scores between the experimental ponds and source populations were calculated and compared against the range of body shapes found on the archipelago.

\section{ECOLOGICAL ASSOCIATIONS AND BODY SHAPE}

A principal component analysis of $\ln$ transformed lake biophysical data (Table I) was performed. The first component explained $38.9 \%$ of the total variation and represented mainly lake morphometry, while the second component explained $25 \cdot 2 \%$ of the total variation and represented lake chemistry. Previous work has shown lake types within each geographical region are more similar than lake types between regions (Reimchen, $1989,1992 b)$.

Body shape variables (CV1 and CV2) were regressed against the principal components to look for potential ecological relationships with body shape. The data were also partitioned to determine whether there was concordance among geographical regions.

The Japanese (trans-North Pacific) three-spined stickleback mitochondrial haplotype occurs in some of the Haida Gwaii populations primarily from the lowlands (O'Reilly et al., 1993; Deagle et al., 1996). Tests were performed (ANCOVA) to determine whether there were any body shape and habitat (PC1 and PC2) associations between populations with and without the Japanese haplotype.

Tests were performed to determine whether body shape could be predicted by the predation regime of the habitat. Predator state is defined as either salmonid or bird and invertebrate (Reimchen, 1994). Body shape and predation were examined for the whole archipelago, for each geographical region and for presence of European and

TABle I. Principal component matrix of loading scores for physical characteristics of lake habitat $(n=70)$ on Haida Gwaii, British Columbia. PC1 explains $38.9 \%$ of the variation among habitats and represents lake morphometry and PC2 explains $25 \cdot 2 \%$ of the variation and represents lake chemistry or conductivity. All of the variables except $\mathrm{pH}$ and T400 were $\ln$ transformed prior to the principal component analysis

\begin{tabular}{lrc}
\hline Variable & $\begin{array}{r}\text { Lake morphometry } \\
(\mathrm{PC} 1)\end{array}$ & $\begin{array}{c}\text { Lake chemistry } \\
(\mathrm{PC} 2)\end{array}$ \\
\hline $\mathrm{pH}$ & $0 \cdot 66$ & $0 \cdot 57$ \\
Conductivity & $-0 \cdot 20$ & $0 \cdot 75$ \\
Calcium & $0 \cdot 10$ & $0 \cdot 86$ \\
T400 & $-0 \cdot 70$ & $-0 \cdot 44$ \\
Depth & $0 \cdot 93$ & $-0 \cdot 18$ \\
Area & $0 \cdot 86$ & $-0 \cdot 29$ \\
Volume & $0 \cdot 92$ & $-0 \cdot 26$ \\
Elevation & $0 \cdot 18$ & $-0 \cdot 32$ \\
Distance from the ocean & $-0 \cdot 23$ & $-0 \cdot 39$ \\
\hline
\end{tabular}


North American mtDNA haplotype in lowland lakes. The five lowland populations with the Japanese mtDNA haplotype present do not have salmonid predation; therefore, any ecological relationship detected in the presence of the Japanese haplotype includes effects of bird and invertebrate predation.

\section{RESULTS}

\section{QUANTIFICATION OF BODY SHAPE}

Discriminant function analysis on partial warp and uniform component scores predicted group membership (i.e. lake sample) $83.7 \%$ of the time. The first CV accounted for $34.7 \%$ of the total variation and contrasted more derived fish on the negative extent of the vector, characterized by thick peduncles, posterior and closely spaced dorsal spines, anterior pelvis and small dorsal and anal fins (Table II), represented by Rouge Lake [Fig. 4(a)] with ancestral marine three-spined stickleback [Fig. 4(b)], on the positive end of the vector with a small narrow peduncle, anterior and widely spaced dorsal spines, posterior pelvis and large dorsal and anal fins. The second vector accounted for $20.3 \%$ of the total variation and contrasted derived three-spined stickleback with negative loadings characterized by small heads and shallow bodies, represented by Mayer Lake [Fig. 4(c)] with less derived fish with large heads and deeper bodies, represented by fish from Fairfax Lake [Fig. 4(d)].

TABLE II. Pearson correlations for CV1 and CV2 between ln linear regression standardized morphometric measurement calculated from inter-landmark distances for 118 populations of adult three-spined stickleback from Haida Gwaii, British Columbia. CV1 explained $33.4 \%$ of the variation among populations of adult stickleback, and CV2 explained $21.7 \%$ of the variation

\begin{tabular}{lccccc}
\hline & \multicolumn{2}{c}{ CV1 } & & \multicolumn{2}{c}{ CV2 } \\
\cline { 2 - 3 } \cline { 5 - 6 } Character & $\begin{array}{c}\text { Pearson correlation } \\
(r)\end{array}$ & $P$ & Pearson correlation & $P$ \\
value & $(r)$ & value \\
\hline Pelvis & 0.69 & $<0.001$ & & 0.42 & $<0.001$ \\
Pelvis position & 0.62 & $<0.001$ & & 0.63 & $<0.001$ \\
Head area & 0.16 & 0.09 & & 0.49 & $<0.001$ \\
Head length & 0.42 & $<0.001$ & & 0.48 & $<0.001$ \\
Head depth & 0.04 & 0.68 & & 0.58 & $<0.001$ \\
Gape & -0.10 & 0.29 & & 0.15 & 0.11 \\
Dorsal spine 1 (D1) position & -0.41 & $<0.001$ & & 0.20 & 0.03 \\
Distance between D1 and D2 & 0.92 & $<0.001$ & & 0.44 & $<0.001$ \\
Body depth (anterior) & 0.26 & 0.005 & & 0.38 & $<0.001$ \\
Body depth (posterior) & 0.08 & 0.37 & & 0.25 & 0.007 \\
Dorsal fin length & 0.35 & $<0.001$ & & -0.04 & 0.64 \\
Anal fin length & 0.47 & $<0.001$ & -0.29 & 0.002 \\
Caudal depth (anterior) & -0.08 & 0.37 & & 0.04 & 0.7 \\
Caudal depth (posterior) & -0.64 & $<0.001$ & -0.25 & 0.005 \\
Caudal peduncle size & -0.72 & $<0.001$ & -0.41 & $<0.001$ \\
\hline
\end{tabular}



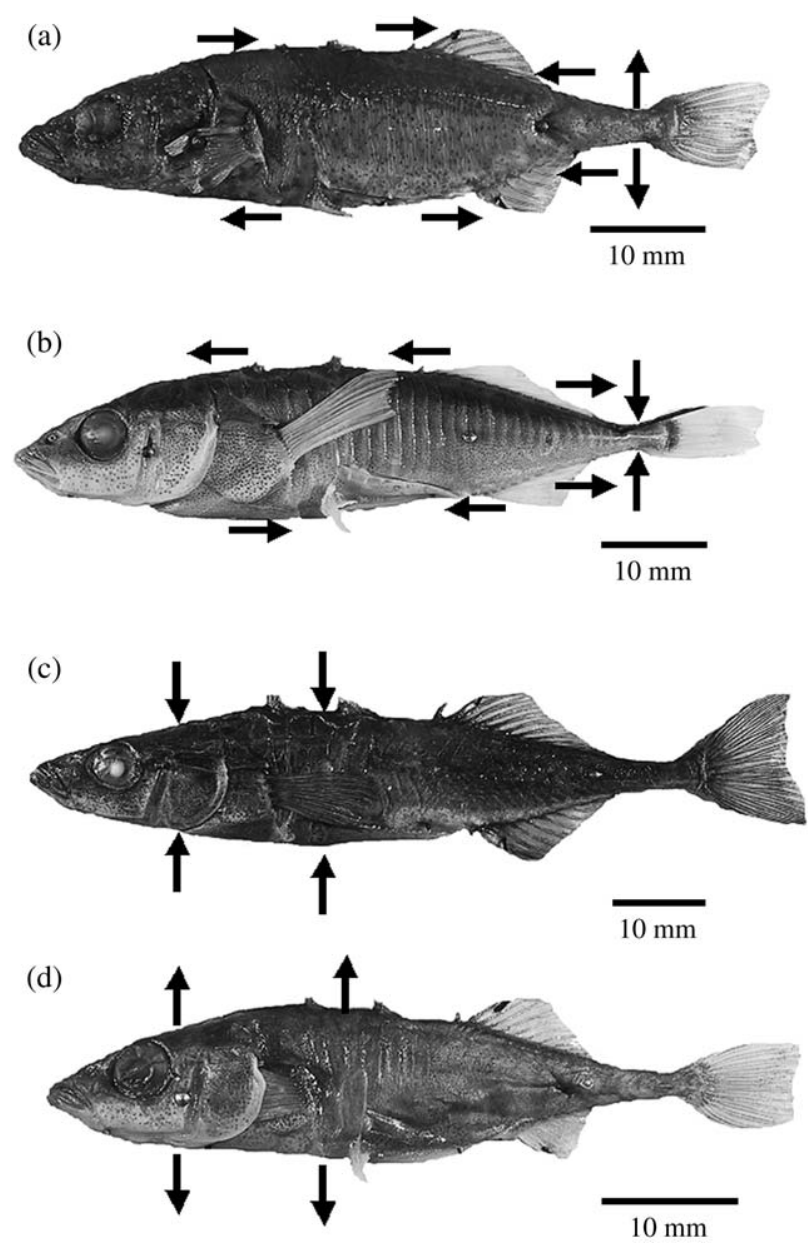

FIG. 4. Photographs of representative adult male three-spined stickleback from: (a) Rouge Lake (CV1-), (b) Entry Point $(\mathrm{CV} 1+)$, (c) Mayer Lake (CV2-) and (d) Fairfax Lake (CV2+). Arrows indicate differences in shape as quantified by canonical vectors.

There were significant differences among population in the mean body shapes (ANOVA, CV1: $F_{118,1302}, P<0.001$; CV2: $F_{118,1302}, P<0.001$; Fig. 5).

Adult body size differed among the populations $\left(30-115 \mathrm{~mm} L_{\mathrm{S}}\right)$, so tests were conducted to determine whether there were any corresponding differences in body shape. The first vector was not significantly correlated with centroid size $(n=118, r=0 \cdot 13, P>0 \cdot 05)$. Body shape means (CV2) for each population, however, were negatively correlated with adult body size $(n=118$, $r=-0.48, P<0.001$ ), showing that larger fish at the negative extreme of $\mathrm{CV} 2$ had a more derived shape than the marine ancestral populations.

\section{ESTIMATES OF PHENOTYPIC PLASTICITY IN BODY SHAPE}

Differences in body shape between source and transplanted populations of three-spined stickleback were detected. The first generation of three-spined 


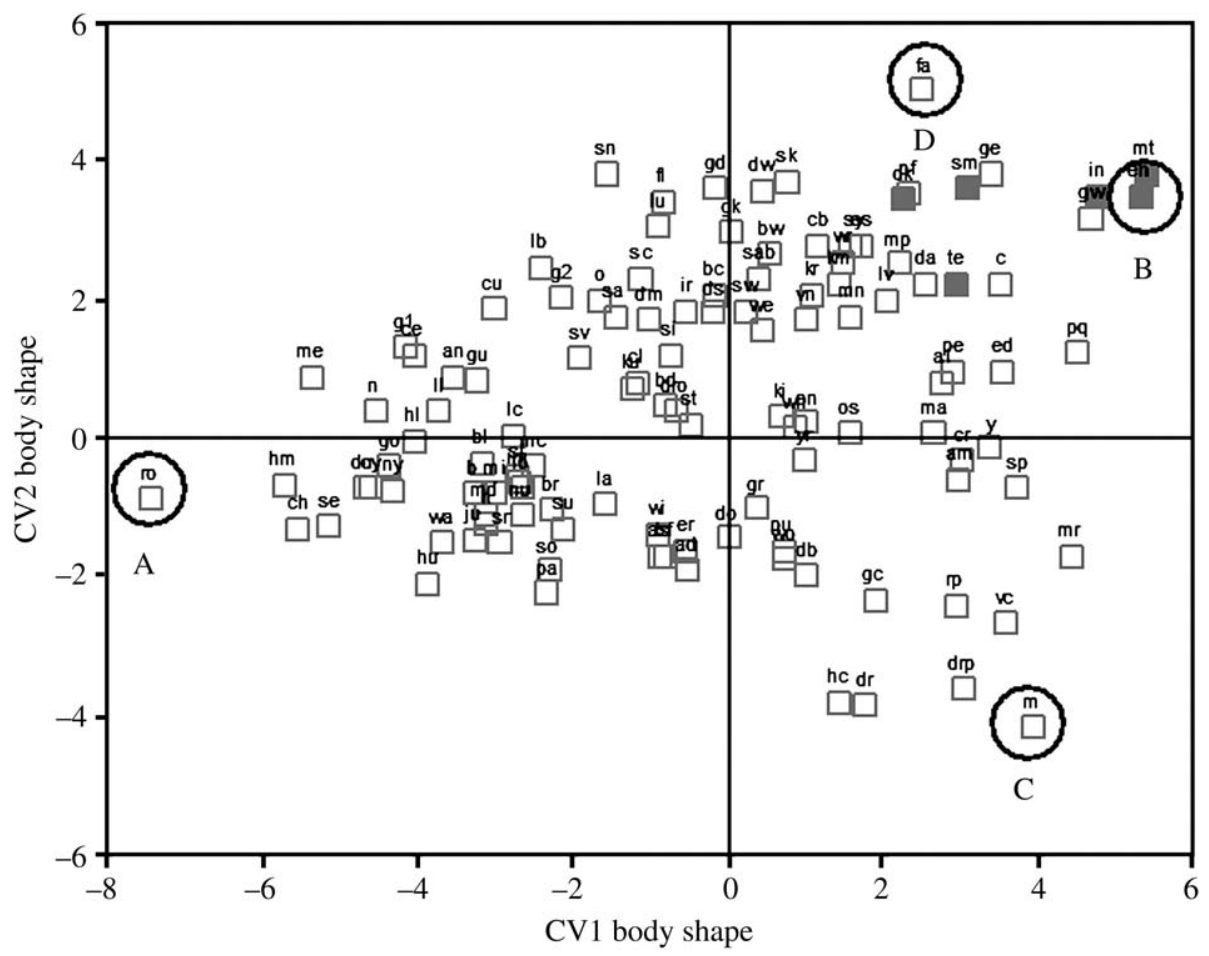

FIG. 5. Body shape quantified by canonical vector $1(33 \cdot 4 \%$ of total variation) and canonical vector 2 $(21.7 \%$ of total variation) of adult male three-spined stickleback from Haida Gwaii. $\square$, Anadromous populations. Populations with extreme shape are A, Rouge Lake; B, Entry Point; C, Mayer Lake; D, Fairfax Lake.

stickleback from Drizzle experimental pond $(n=22)$ had marginally higher positive loadings for CV1 and CV2 than did the source population $(n=25)$ and differed by $11 \cdot 3 \%$ of the total CV1 variation and $4 \cdot 6 \%$ of the CV2 variation among Haida Gwaii populations. Similar results occurred for the transplanted population from Mayer Lake. Although visually indistinguishable, the first generation from the experimental pond $(n=8)$ had slightly higher CV1 and CV2 values relative to the source population $(n=38)$ and differed by $3.9 \%$ of the total CV1 variation and $9.4 \%$ of the CV2 variation among Haida Gwaii populations. Body shape was examined following 10 years of habitation and yearly reproduction in the experimental ponds. There were no further shifts in CV1 or CV2 for the Drizzle experimental pond. At the Mayer experimental pond $(n=11)$, however, there was a slight increase in both CV1 and CV2 relative to the source population, which accounted for $8.9 \%$ of total CV1 variation and $21 \cdot 2 \%$ of total CV2 variation among all Haida Gwaii populations.

\section{BODY SHAPE AND ECOLOGICAL ASSOCIATIONS}

Derived fish with high negative loadings of CV1 (thick peduncles, posterior positioned and closely spaced dorsal spines, anterior pelvis and small dorsal 
and anal fins) were found in small, shallow, stained ponds (negative PC1 loadings), and less derived three-spined stickleback with high positive loadings (opposite characteristics) were found in large, deep, clear lakes (positive PC1 loadings; linear regression, d.f. $\left.=65, r^{2}=0.45, P<0.001\right)$. The slopes did not differ between geographical region (ANCOVA, $F_{1,64}, P>0.05$; Fig. 6) and between predator grouping within each geographical region (plateau and mountain region: ANCOVA, $F_{1,20}, P>0.05$; lowlands: ANCOVA, $F_{1,39}$, $P>0 \cdot 05)$. Furthermore, the slopes did not differ between mitochondrial haplotypes in lowland populations (ANCOVA, $F_{1,31}, P>0.05$ ).

Body shape (CV1) was also related to the predation regime of a given habitat. Populations of three-spined stickleback from predatory fish lakes had higher $\mathrm{CV}$ values across all lake conditions relative to bird and invertebrate lakes $\left(F_{1,41}, P<0 \cdot 001\right)$. Most of the lakes with bird and invertebrate predators are in the lowlands and when body shape was examined against lake morphometry within this region, the same associations were observed in that three-spined stickleback from predatory fish lakes had higher CV scores relative to bird and invertebrate predation for all lake sizes $\left(F_{1,23}, P<0.001\right)$.

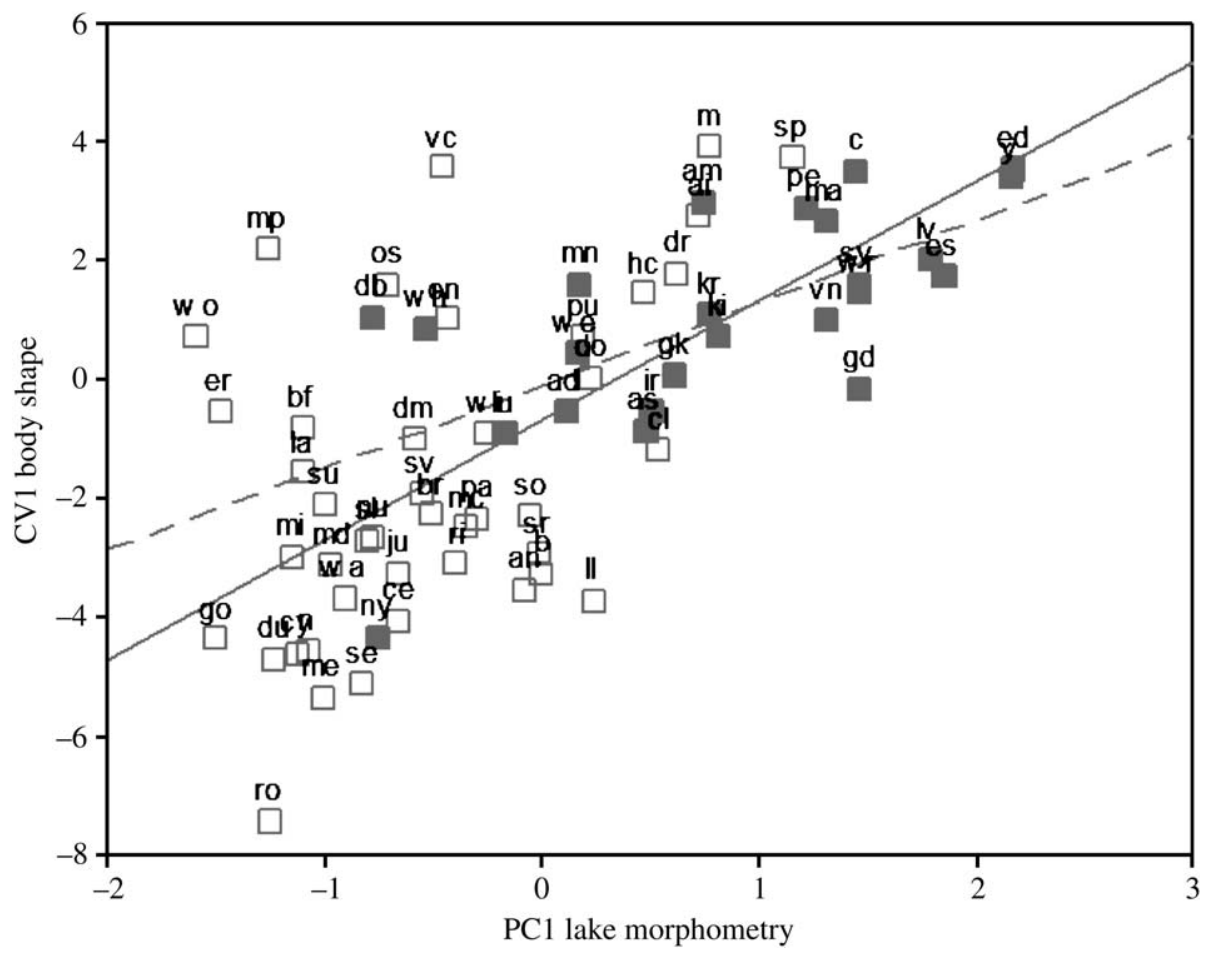

FIG. 6. Relationship between body shape of adult male three-spined stickleback (CV1: $34 \cdot 7 \%$ of total variation), lake morphometry (PC1: 38.9\% of total variation) and geographic region for populations of fish from the lowlands ( $-\square-$ ), and from the plateau and mountain region (-- ---$)$. Lakes that are small, shallow and stained contained three-spined stickleback with derived body shape, compared to large, deep and clear lakes which had less derived fish (overall slope $r^{2}=0 \cdot 45$, d.f. $=65$, $P<0.001$; slope comparisons for geographic region, ANCOVA $F_{1,64}, P>0 \cdot 5$ ). 
Body shape quantified by CV2 could also be predicted by lake chemistry. Three-spined stickleback with derived shape (high negative CV2 loadings) characterized by small heads and shallow bodies were found in habitats with low conductivity (negative PC2 loadings), and fish with less derived shape (high positive CV2 loadings) distinguished by large heads and deeper bodies were often found in lakes of higher conductivity (positive PC2 loadings; linear regression, d.f. $=65, r^{2}=0.22, P<0.001$ ). This relationship was observed when the data were partitioned by geographical area, but a significant interaction effect between lake physical characteristics and geographical region suggests that the relationship is strongest in the lowlands (ANCOVA, $F_{1,63}$, $P<0.001$; Fig. 7). The relationship between shape (CV2) and lake chemistry (PC2) was consistent within lowland populations between mitochondrial haplotypes (ANCOVA, $F_{1,31}, P>0 \cdot 05$ ). Three-spined stickleback with derived shape (high negative CV2 loadings) were found in habitats of low conductivity (negative PC2 loadings) and less derived shape (high positive CV2 loadings) in lakes of higher conductivity (positive PC2 loadings) (Fig. 8).

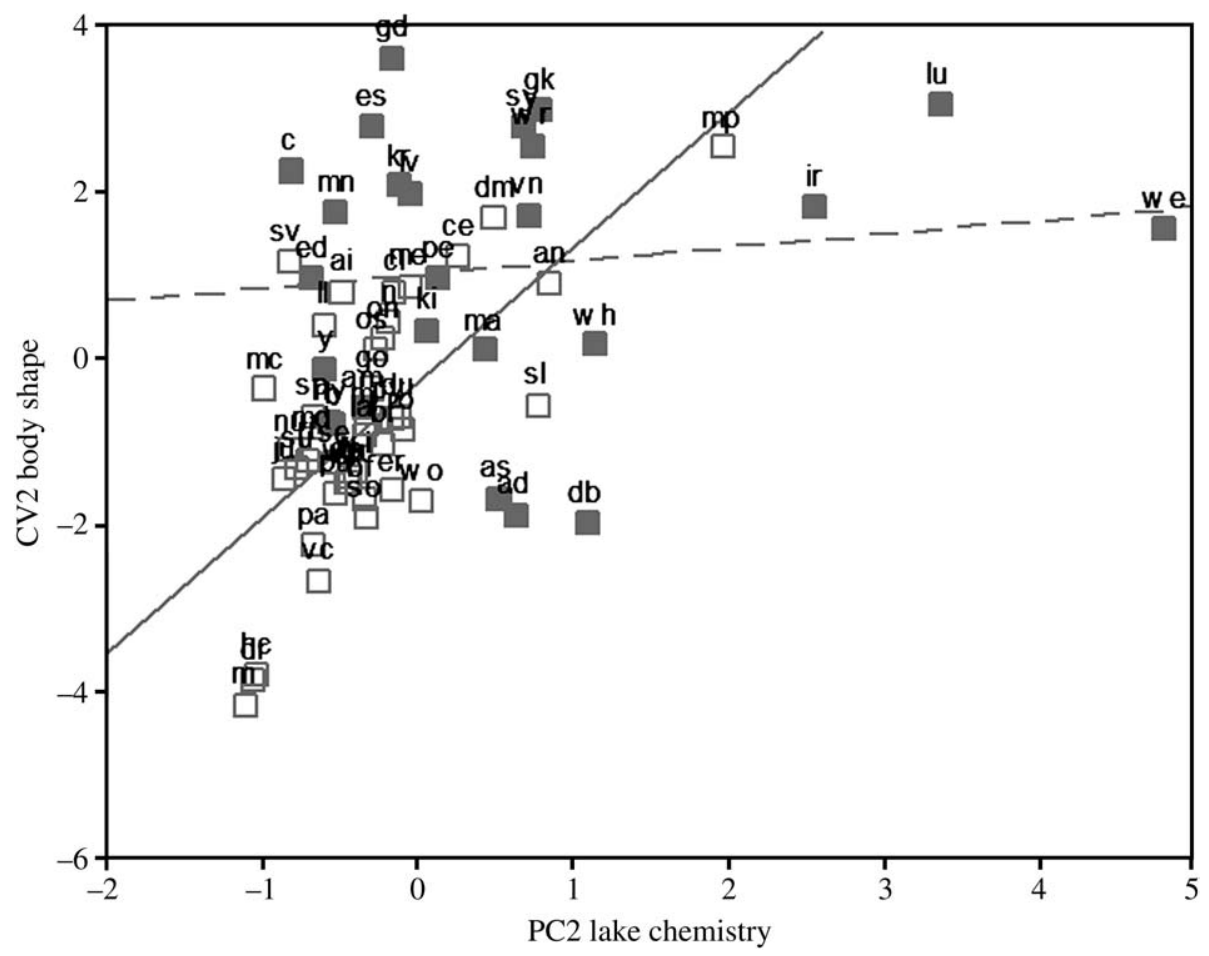

FIG. 7. Relationship between body shape of adult male three-spined stickleback (CV2: $20 \cdot 3 \%$ of total variation), lake chemistry (PC2: $25 \cdot 2 \%$ of total variation) and geographic region for populations of fish from the lowlands ( $-\square-)$, from the plateau and mountain region (-- ---$)$. In each geographic region lakes of low conductivity had derived three-spined stickleback with small heads and shallow bodies compared to lakes of higher conductivity that supported less derived fish with large heads and deeper bodies. The relationship is strongest in the lowlands (lowlands $r^{2}=0 \cdot 45$, d.f. $=42$, plateau and mountain $r^{2}=0 \cdot 02$, d.f. $=23$; slope comparisons for geographical region, ANCOVA $\left.F_{1,63}, P<0 \cdot 001\right)$. 


\section{DISCUSSION}

The modern marine three-spined stickleback has remained morphologically conserved since the Miocene (Bell, 1977; Bell \& Foster, 1994; Walker \& Bell, 2000) and therefore represents the ancestral or less derived condition. The marine populations have streamlined bodies and with extreme positive loadings for CV1 and high positive loadings for CV2, which can be characterized as having large heads, deeper bodies, narrow peduncles, anterior dorsal spines, widely spaced dorsal spines, posterior pelvis and long dorsal and anal fins. Combined, these attributes typify streamlined three-spined stickleback which have evolved in association with the pelagic habitat and migratory lifestyle of these anadromous fish (Wootton, 1976; Taylor \& McPhail, 1986; Walker, 1997).

Coastal freshwater habitats in the circumboreal zone were colonized by marine three-spined stickleback and have diversified since the retreat of the Pleistocene glaciers 10000 years ago (Bell \& Foster, 1994). Morphological diversity in freshwater three-spined stickleback populations has been widely discussed and includes gigantism (Moodie, 1972b; Bell, 1984; Reimchen

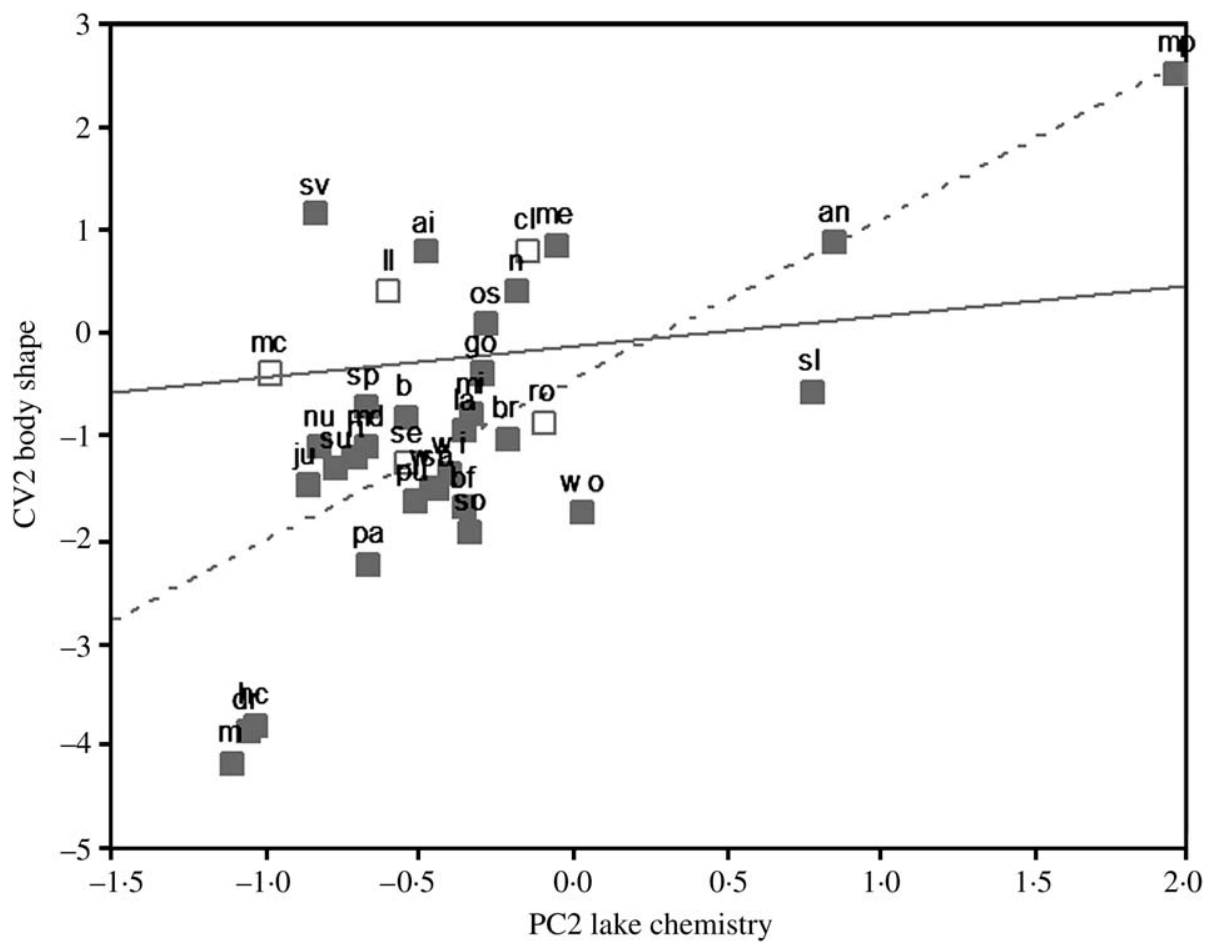

FIG. 8. Relationship between body shape of adult male three-spined stickleback (CV2: $20 \cdot 3 \%$ of total variation), lake chemistry (PC2: $25 \cdot 2 \%$ of total variation) and mtDNA haplotype for populations of fish with the Japanese mtDNA haplotype present $(-\square-)$ and populations that are monomorphic for the Euro and North American mtDNA haplotype (-- - -). Populations within each lineage were less derived in lakes of higher conductivity (European and North American haplotype $r^{2}=$ $0 \cdot 44$, d.f. $=29$, Japanese haplotype $r^{2}=0 \cdot 02$, d.f. $=4$; slope comparisons for mitochondrial lineage, ANCOVA $\left.F_{1,31}, P>0 \cdot 5\right)$. 
et al., 1985), and armour reduction (Reimchen, 1994). Differentiation in body shape of freshwater populations was initially described within lakes for benthic and limnetic ecotypes from south-western British Columbia (McPhail, 1984) and among lakes in Alaskan populations (Walker, 1997; Walker \& Bell, 2000). Although body shape is highly conserved, principal component analysis of 40 Alaskan freshwater populations showed derived three-spined stickleback possessing posterior and closely spaced dorsal spines, short median fins, thick peduncles and anterior positioned pelvic girdle (Walker \& Bell, 2000). The present canonical vector data from 118 Haida Gwaii freshwater populations show concordant trends to those observed by Walker \& Bell (2000) with respect to each of these morphological characters and each principal component factor but encompass a broader range of habitat.

Intraspecific differences in shape observed among freshwater fish populations may reflect heritable or phenotypically plastic traits or some combination of the two. Within cichlids, trophic morphological characters can be highly variable and can be partially explained by differences in diet and phenotypic plasticity (Meyer, 1987; Klingenberg et al., 2003). A slight alteration of growth rates for different bones due to availability and abundance of prey types during development can have substantive effects on adult phenotype (Liem, 1973; Alberch et al., 1979; Meyer, 1987). In the present study, large bodied, highly streamlined three-spined stickleback from a large dystrophic lake with zooplankton and a full suite of vertebrate predators were transplanted to a small and shallow clear-water eutrophic pond with benthic prey and macroinvertebrate predators as a field assessment of environment-dependent phenotypic expression. The subsequent generations of three-spined stickleback in these experimental ponds were very similar in appearance and shape to their parental populations. With detailed shape analysis, however, it was evident that $c .10 \%$ of the variation in body shape among all of the Haida Gwaii three-spined stickleback populations can be attributed to phenotypic plasticity. The possibility exists that there were gene frequency changes within the first generation that resulted in the new phenotype. This seems unlikely, however, given the similarity in body shape within each experimental population after 10 years monitoring.

The body shape of fishes can be expected to be associated with hydrodynamic factors for both foraging and predator evasion. In the analysis of shape in Alaskan populations, Walker (1997) found that three-spined stickleback from deep lakes were streamlined, those from shallow lakes had deeper body shape, but these effects were accentuated in populations with the presence of native predatory fishes. On Haida Gwaii, there was a similar association, but the relationship between shape and lake depth was also found in lakes without native predatory fishes. Specifically, the body shapes of three-spined stickleback found in large, deep lakes were similar to that of marine three-spined stickleback in adjacent waters. As such, where the freshwater habitat was similar to that of the marine three-spined stickleback (large and deep with zooplankton as the primary food source), the body shape was conserved. Populations of threespined stickleback in habitats least like the marine environment (small, shallow and stained ponds with benthic prey) had the most divergent body shapes. Throughout Haida Gwaii, populations of three-spined stickleback subject to predation regimes most similar to the ancestral marine (toothed predators such 
as salmonids) had less derived attributes of shape, while populations subject to predation from primarily birds and macroinvertebrates had derived body shape. What is most important is that populations from either predation regime (primarily salmonids or bird and invertebrate) had characteristics of the less derived streamlined-shape in larger, deeper, clearer lakes and more derived attributes of shape (towards CV1-) when found in smaller, shallower, stained ponds, highlighting the efficacy of hydrodynamic processes on the evolution of shape.

The streamlined shape of three-spined stickleback inhabiting large lakes is conducive to lower pressure drag during steady swimming and should therefore increase open water foraging performance (Aleev, 1977; Vogel, 1981; Webb, 1984; Walker, 1997). Patchily distributed zooplankton (George, 1981; PinelAlloul et al., 1988) are the primary food source in large deep lakes (Hart \& Gill, 1994) and in large lakes of low conductivity (Moodie, 1972a; Moodie \& Reimchen, 1976b). Therefore, three-spined stickleback in such habitats would have to constantly swim to find food, which increases the risk of predation by limiting the amount and type of cover. The large median fins of populations with less derived body shape effectively increase caudal depth, without the additive affects of drag associated with a thick caudal peduncle (Walker, 1997), thus facilitating prey capture and increasing the probability of escape from predators (salmonids and birds and invertebrates) with improved fast start performance (Reimchen, 1992a; Bergstrom, 2002). Long median fins of the streamlined three-spined stickleback in the marine and open water habitats suggest stabilizing selection has maintained this less derived condition in freshwater three-spined stickleback that forage in open water (Walker, 1997).

In contrast, freshwater three-spined stickleback found in small and shallow ponds, which are most different from marine habitat, were derived and distinctive from the marine form. Small shallow ponds offer habitats that are very heterogeneous compared to the uniformity of the open water environment (Hart \& Gill, 1994). The larvae and pupae of the Chironomidae are the primary food source in littoral habitats (Wootton, 1994), and the rate at which three-spined stickleback encounter prey is strongly influenced by the density and structural complexity of woody debris through which they must search (Hart \& Gill, 1994). Predation experiments indicate that structural complexity in littoral areas can provide a refuge from predators, and predation risk can affect both choice of feeding site and the amount and type of prey eaten (Werner et al., 1983a, b; Ibrahim \& Huntingford, 1989). The shorter median fins of populations found in small shallow ponds potentially compromise acceleration (Aleev, 1977). Benthic prey, however, are relatively sedentary and do not require the same fast acceleration that three-spined stickleback exhibit in attack in pelagic habitats (Walker, 1997). Possibly, the fin reduction is associated with calcium limitations and bone reduction (Giles, 1983; Bourgeois et al., 1994) or to reduced surface area as a result of selection from grappling macroinvertebrates (Reimchen, 1980).

The ecomorphological relationships were similar in both the lowland and plateau and mountain regions, and between the two mitochondrial haplotypes in the lowland region, suggesting the parallel evolution of body shape through adaptations to similar hydrodynamic landscapes and selection regimes imposed by habitat. The associations exhibited by the Haida Gwaii three-spined stickleback 
are consistent with results from previous studies, which link body shape adaptations to multiple aspects of ecology in Alaskan three-spined stickleback populations (Walker, 1997; Walker \& Bell, 2000) and to other three-spined stickleback populations of the world (Hermida et al., 2005). The body shape associations detected in this study are also consistent with those reported for feeding habits in serranids (Cavalcanti et al., 1999) and populations of cichlids (Klingenberg et al., 2003). Population body shape differentiation has been shown to occur as a response to predation in poecilids (Langerhans et al., 2004; Langerhans \& DeWitt, 2004), as well as cyprinids (Brönmark \& Miner, 1992).

What has happened after 10000 years of evolution? On Haida Gwaii, the three-spined stickleback has colonized 118 lakes comprising a wide variety of isolated habitats and has diversified in maximum body size (Reimchen, 1991), nuptial colouration (Reimchen, 1989) and defensive morphology (Moodie \& Reimchen, 1976a; Reimchen et al., 1985), yet has maintained a relatively conserved body shape. Haplochrome cichlids from Lake Victoria in East Africa have diversified within the last 15000 years into $>500$ endemic species (Seehausen, 2002; Verheyen et al., 2003), which inhabit adaptive zones throughout the lake (Liem, 1973) and exhibit marked differences in body shape (Stiassny \& Meyer, 1999; Joyce et al., 2005). The results of the present study on threespined stickleback from Haida Gwaii suggest that a phenotypic integration conserves body shape, but responds to biophysical processes, indicating local adaptation to the foraging, predator and hydrodynamic landscape in the adaptive radiation of fishes.

We thank M. A. Bell for discussion, S. Douglas for field assistance and the Natural Sciences and Engineering Council of Canada for support (operating grant NRC2354 to T.E.R.). The research on body shape is part of an MSc thesis prepared by M.A.S.

\section{References}

Alberch, P., Gould, S. J., Oster, G. F. \& Wake, D. B. (1979). Size and shape in ontogeny and phylogeny. Paleobiology 5, 296-317.

Aleev, I. U. G. (1977). Nekton. The Hague: Junk.

Andersson, J. (2003). Effects of diet-induced resource polymorphism on performance in arctic charr (Salvelinus alpinus). Evolutionary Ecology Research 5, 213-228.

Baumgartner, J. V. (1992). Spatial variation in a freshwater population of the threespine stickleback, Gasterosteus aculeatus. Canadian Journal of Zoology 70, 1140-1148.

Baumgartner, J. V., Bell, M. A. \& Weinberg, P. H. (1988). Body form differences between the Enos Lake species pair of threespine sticklebacks (Gasterosteus aculeatus complex). Canadian Journal of Zoology 66, 467-474.

Bell, M. A. (1977). Late Miocene marine threespine stickleback, Gasterosteus aculeatus aculeatus, and its zoogeographic and evolutionary significance. Copeia 1977, 277-282.

Bell, M. A. (1984). Gigantism in threespine sticklebacks - implications for causation of body size evolution. Copeia 1984, 530-534.

Bell, M. A. \& Foster, S. A. (1994). Introduction to the evolutionary biology of the threespine stickleback. In The Evolutionary Biology of the Threespine Stickleback (Bell, M. A. \& Foster, S. A., eds), pp. 1-27. Oxford: Oxford University Press.

Bergstrom, C. A. (2002). Fast-start performance and reduction in lateral plate number in threespine stickleback. Canadian Journal of Zoology 80, 207-213.

Bergstrom, C. A. \& Reimchen, T. E. (2002). Geographical variation in asymmetry in Gasterosteus aculeatus. Biological Journal of the Linnean Society 77, 9-22. 
Boag, P. T. \& Grant, P. R. (1981). Intense natural selection in a population of Darwin's finches (Geospizinae) in the Galápagos. Science 214, 82-85.

Bookstein, F. L. (1991). Morphometric Tools for Landmark Data: Geometry and Biology. Cambridge: Cambridge University Press.

Bookstein, F. L. (1996). Combining the tools of geometric morphometrics. In Advances in Morphometrics (Marcus, L. F., Corti, M., Loy, A., Naylor, G. J. P. \& Slice, D. E., eds), pp. 131-151. New York: Plenum Press.

Bourgeois, J. F., Blouw, D. M., Koenings, J. P. \& Bell, M. A. (1994). Multivariateanalysis of geographic covariance between phenotypes and environments in the threespine stickleback, Gasterosteus aculeatus, from the Cook Inlet area, Alaska. Canadian Journal of Zoology 72, 1497-1509.

Breder, C. M. J. (1926). The locomotion of fishes. Zoologica 4, 159-297.

Brönmark, C. \& Miner, J. G. (1992). Predator-induced phenotypical change in body morphology in crucian carp. Science 258, 1348-1350.

Cavalcanti, M. J., Monteiro, L. R. \& Lopes, P. R. D. (1999). Landmark-based morphometric analysis in selected species of Serranid fishes (Perciformes: Teleostei). Zoological Studies 38, 287-294.

Deagle, B. E., Reimchen, T. E. \& Levin, D. B. (1996). Origins of endemic stickleback from the Queen Charlotte Islands: mitochondrial and morphological evidence. Canadian Journal of Zoology 74, 1045-1056.

George, D. G. (1981). Zooplankton patchiness. Annual Report of the Freshwater Biological Association 49, 32-44.

Giles, N. (1983). The possible role of environmental calcium levels during the evolution of phenotypic diversity in Outer Hebridean populations of the threespined stickleback (Gasterosteus aculeatus). Journal of Zoology 199, 535-544.

Grant, P. R. \& Grant, B. R. (1995). Predicting microevolutionary responses to directional selection on heritable variation. Evolution 49, 241-251.

Grant, P. R., Grant, B. R., Smith, J. N. M., Abbott, I. J. \& Abbott, L. K. (1976). Darwin's finches: population variation and natural selection. Proceedings of the National Academy of Science 1973, 257-261.

Guill, J. M., Heins, D. C. \& Hood, C. S. (2003a). The effect of phylogeny on interspecific body shape variation in darters (Pisces: Percidae). Systematic Biology 52, 488-500.

Guill, J. M., Hood, C. S. \& Heins, D. C. (2003b). Body shape variation within and among three species of darters (Perciformes: Percidae). Ecology of Freshwater Fish 12, 134-140.

Hart, P. J. B. \& Gill, A. B. (1994). Evolution of foraging behavior in the threespine stickleback. In The Evolutionary Biology of the Threespine Stickleback (Bell, M. A. \& Foster, S. A., eds), pp. 207-239. Oxford: Oxford University Press.

Hermida, M., Fernández, C., Amaro, R. \& San Miguel, E. (2005). Morphometric and meristic variation in Galician threespine stickleback populations, NW Spain. Environmental Biology of Fishes 73, 189-200.

Ibrahim, A. A. \& Huntingford, F. A. (1989). Laboratory and field studies of the effect of predation risk on foraging in 3-spined sticklebacks (Gasterosteus aculeatus). Behaviour 109, 46-57.

Joyce, D. A., Lunt, D. H., Bills, R., Turner, G. F., Katongo, C., Duftner, N., Sturmbauer, C. \& Seehausen, O. (2005). An extant cichlid fish radiation emerged in an extinct Pleistocene lake. Nature 435, 90-95.

Klingenberg, C. P., Barluenga, M. \& Meyer, A. (2003). Body shape variation in cichlid fishes of the Amphilophus citrinellus species complex. Biological Journal of the Linnean Society 80, 397-408.

Lack, D. (1947). Darwin's Finches. New York: Harper and Row (reprint 1961).

Langerhans, R. B. \& DeWitt, T. J. (2004). Shared and unique features of evolutionary diversification. American Naturalist 164, 335-349.

Langerhans, R. B., Layman, C. A., Langerhans, A. \& DeWitt, T. J. (2003). Habitatassociated morphological divergence in two Neotropical fish species. Biological Journal of the Linnean Society 80, 689-698.

Langerhans, R. B., Layman, C. A., Shokrollahi, A. M. \& DeWitt, T. J. (2004). Predator driven phenotypic diversification in Gambusia affinis. Evolution 58, 2305-2318. 
Liem, K. F. (1973). Evolutionary strategies and morphological innovations: cichlid pharyngeal jaws. Systematic Zoology 22, 425-441.

Losos, J. B. (1990). The evolution of form and function: morphology and locomotor performance in West Indian Anolis lizards. Evolution 44, 1189-1203.

McGuigan, K., Franklin, C. E., Moritz, C. \& Blows, M. W. (2003). Adaptation of rainbow fish to lake and stream habitats. Evolution 57, 104-118.

McPhail, J. D. (1984). Ecology and evolution of sympatric stickleback (Gasterosteus): morphological and genetic evidence for a pair in Enos Lake, British Columbia. Canadian Journal of Zoology 62, 1402-1408.

Meyer, A. (1987). Phenotypic plasticity and heterochrony in Cichlasoma managuense (Pisces, Cichlidae) and their implication for speciation in cichlid fishes. Evolution 41, 1357-1369.

Moodie, G. E. E. (1972a). Morphology, life-history, and ecology of an unusual stickleback (Gasterosteus aculeatus) in Queen-Charlotte Islands, Canada. Canadian Journal of Zoology 50, 721-732.

Moodie, G. E. E. (1972b). Predation, natural-selection and adaptation in an unusual 3 spine stickleback. Heredity 28, 155-167.

Moodie, G. E. E. \& Reimchen, T. E. (1976a). Phenetic variation and habitat differences in Gasterosteus populations of the Queen Charlotte Islands. Systematic Zoology 25, 49-61.

Moodie, G. E. E. \& Reimchen, T. E. (1976b). Glacial refugia, endemism, and stickleback populations of Queen Charlotte Islands, British-Columbia. Canadian FieldNaturalist 90, 471-474.

O'Reilly, P., Reimchen, T. E., Beech, R. \& Strobeck, C. (1993). Mitochondrial-DNA in Gasterosteus and Pleistocene glacial refugium on the Queen-Charlotte-Islands, British-Columbia. Evolution 47, 678-684.

Orti, G., Bell, M. A., Reimchen, T. E. \& Meyer, A. (1994). Global survey of mitochondrial-DNA sequences in the threespine stickleback - evidence for recent migrations. Evolution 48, 608-622.

Pinel-Alloul, B., Downing, J. A., Perusse, M. \& Codin-Blumer, G. (1988). Spatial heterogeneity in freshwater zooplankton: variation with body size, depth, and scale. Ecology 69, 1393-1400.

Reidy, S. P., Kerr, S. R. \& Nelson, J. A. (2000). Aerobic and anaerobic swimming performance of individual Atlantic cod. Journal of Experimental Biology 203, 347-357.

Reimchen, T. E. (1980). Spine deficiency and polymorphism in a population of Gasterosteus aculeatus: an adaptation to predators? Canadian Journal of Zoology 58, $1232-1244$.

Reimchen, T. E. (1989). Loss of nuptial color in threespine sticklebacks (Gasterosteus aculeatus). Evolution 43, 450-460.

Reimchen, T. E. (1991). Trout foraging failures and the evolution of body size in stickleback. Copeia 1991, 1098-1104.

Reimchen, T. E. (1992a). Injuries on stickleback from attacks by a toothed predator (Oncorhynchus) and implications for the evolution of lateral plates. Evolution 46, 1224-1230.

Reimchen, T. E. (1992b). Naikoon Provincial Park, Queen Charlotte Islands: Biophysical Data for Freshwater Habitats. Victoria, BC: Ministry of the Environment.

Reimchen, T. E. (1994). Predators and evolution in threespine stickleback. In Evolution of the Threespine Stickleback (Bell, M. A. \& Foster, S. A., eds), pp. 240-276. Oxford: Oxford University Press.

Reimchen, T. E., Stinson, E. M. \& Nelson, J. S. (1985). Multivariate differentiation of parapatric and allopatric populations of threespine stickleback in the Sangan River watershed, Queen Charlotte Islands. Canadian Journal of Zoology 63, 2944-2951.

Rohlf, F. J. (1990). Morphometrics. Annual Review of Ecology and Systematics 21, 299-316.

Rohlf, F. J. (1993). Relative warp analysis and an example of its application to mosquito wings. In Contributions to Morphometrics (Marcus, L. F., Bello, E. \& 
Garcia-Valdecasas, A., eds), pp. 131-159. Madrid: Monografias del Museo Nacional de Ciencias Naturales.

Rohlf, F. J. (1996). Morphometric spaces, shape components and the effects of linear transformations. In Advances in Morphometrics (Marcus, L. F., Corti, M., Loy, A., Naylor, G. J. P. \& Slice, D. E., eds), pp. 117-129. New York: Plenum Press.

Rohlf, F. J. (1999). Shape statistics: procrustes superimpositions and tangent spaces. Journal of Classification 16, 197-223.

Rohlf, F. J. (2000). TPSRegr, 1.25. Stony Brook, NY: Department of Ecology and Evolution, State University of New York at Stony Brook.

Rohlf, F. J. (2004). TPSDig, 1.4. Stony Brook, NY: Department of Ecology and Evolution, State University of New York at Stony Brook.

Schlichting, C. D. (1989). Phenotypic integration and environmental change. Bioscience 39, $460-464$.

Seehausen, O. (2002). Patterns in fish radiation are compatible with Pleistocene desiccation of Lake Victoria and 14600 year history for its cichlid species flock. Proceedings of the Royal Society of London Series B 269, 491-497.

Sfakoitakis, M., Lane, D. M. \& Davies, B. C. (1999). Review of swimming modes for aquatic locomotion. IEEE Journal of Oceanic Engineering 24, 237-252.

Southwood, T. R. E. (1977). Habitat, templet for ecological strategies. Journal of Animal Ecology 46, 337-365.

Stiassny, M. L. J. \& Meyer, A. (1999). Cichlids of the rift lakes. Scientific American 280, 64-69.

Strauss, R. E. \& Bookstein, F. L. (1982). The truss: body form reconstruction in morphometrics. Systematic Zoology 31, 113-135.

Swain, D. P. (1992). The functional basis of natural-selection for vertebral traits of larvae in the stickleback Gasterosteus aculeatus. Evolution 46, 987-997.

Taylor, E. B. \& McPhail, J. D. (1986). Prolonged and burst swimming in anadromous and fresh-water threespine stickleback, Gasterosteus aculeatus. Canadian Journal of Zoology 64, 416-420.

Townsend, C. R. \& Hildrew, A. G. (1994). Species traits in relation to a habitat templet for river systems. Freshwater Biology 31, 265-275.

Verheyen, E., Salzburger, W., Snoeks, J. \& Meyer, A. (2003). Origin of the superflock of cichlid fishes from Lake Victoria, East Africa. Science 300, 325-329.

Vogel, S. (1981). Life in Moving Fluids: The Physical Biology of Flow. Boston, MA: W. Grant Press.

Walker, J. A. (1997). Ecological morphology of lacustrine threespine stickleback Gasterosteus aculeatus L (Gasterosteidae) body shape. Biological Journal of the Linnean Society 61, 3-50.

Walker, J. A. \& Bell, M. A. (2000). Net evolutionary trajectories of body shape evolution within a microgeographic radiation of threespine sticklebacks (Gasterosteus aculeatus). Journal of Zoology 252, 293-302.

Webb, P. W. (1982). Locomotor patterns in the evolution of actinopterygian fishes. American Zoologist 22, 329-342.

Webb, P. W. (1984). Body form, locomotion and foraging in aquatic vertebrates. American Zoologist 24, 107-120.

Werner, E. E., Gilliam, J. F., Hall, D. J. \& Mittelbach, G. G. (1983a). Experimental tests of optimal habitat use in fish: the role of relative habitat profitability. Ecology 64, 1525-1539.

Werner, E. E., Gilliam, J. F., Hall, D. J. \& Mittelbach, G. G. (1983b). An experimental test of the effects of predation risk on habitat use in fish. Ecology 64, $1540-1548$.

Williams, E. E. (1969). The ecology of colonization as seen in the zoogeography of anoline lizards on small islands. The Quarterly Review of Biology 44, 345-389.

Williams, E. E. (1972). The origin of faunas. Evolution of lizard congeners in a complex island fauna: a trial analysis. Evolutionary Biology 6, 47-89.

Wootton, R. J. (1976). The Biology of the Sticklebacks. New York: Academic Press. 
Wootton, R. J. (1994). Energy allocation in the threespine stickleback. In The Evolutionary Biology of the Threespine Stickleback (Bell, A. M. \& Foster, S. A., eds), pp. 114-143. Oxford: Oxford University Press.

\section{ApPEndix. DEFINITION OF SITE ABBREVIATIONS}

ai $\ddagger$, Ain; am, Amber; ad, Anderson North; as, Anderson South; an, Anser; bf $\ddagger$, Bigfish; bw $\ddagger$, Blackwater Creek; bl, Blowdown; bd $\ddagger$, Blue Danub; b, Boulton; br, Branta; bc, Brent Creek; cb, Cape Ball; ce, Cedar; ch $\ddagger$, Chown Creek; cl, Clearwater; c, Coates; cr \$, Copper River; cu \$. Cumshewa; cy \$, Cygnet; dm \$, Dam; da, Darwin; dw \$, Dawson Pond; dt †, Dead Toad Creek; db $\ddagger$, Debris; dk $\ddagger$, Delkatla; ds $\ddagger$, Desolate; do + , Down tree; dr, Drizzle; dro, Drizzle Outlet Creek; drp, Drizzle Pond; du \$, Duck; ed, Eden; en, Entry Point; er \$, Eriophore; es, Escarpment; fa \$, Fairfax; fl, Florence Creek; g1, Geike Creek; g2 †, Geike \#2 Creek; gc †, Gold Creek; gk †, Goski; go \$, Gosling; ge \$. Gowgaia; gw †, Gowgaia West; gr, Gross; gu, Grus; gd, Gudal; hu †, Harelda Upper; hl, Heralda Lower; hm, Heralda Middle; hc \$, Hickey; im, Imber; in, Inskip Lagoon; ir, Irridens; ju, Juno; ki, Kiokathli; kr †, Krajina; ku, Kumara; km, Kumdis Creek; lb, Labrador Creek; la \$, Laurel Pond; lo \$, Loon; lc †. Loon Creek; lv, Lower Victoria; 1l, Lumme; lls †, Lumme Swamp Creek; lu, Lutea; ma $\ddagger$, Marie; mr, Marion; mt, Masset Inlet; m, Mayer; mn, Menyanthes; me + , Mesa; mc, Mica; mi $\downarrow$, Middle; md, Midge; mp, Molitors Pond; ms †, Mosquito; $\mathrm{n} \downarrow$, Naked; ny, New Years; nu, Nuphar; o \$, Oeanda River; on, Otter North; os, Otter South; pa, Parkes; pe $\ddagger$, Peter; pc $\dagger$, Pontoon Center; pq, Poque; pf, Puffin; pu, Pure; ri $\$$, Richter; rp, Mayer Pond; ro, Rouge; sa †, Sangan River; sab \$. Sangan Backwater River; si, Seal Inlet; se, Serendipity; sm, Sheldon Meadows; sv, Silver; sk †, Skaters; sg †, Skidgate; s †, Skonun; sl, Slim; sn \$, Snub; so, Solstice; sp, Spence; sr, Spraint; st \$, Stellata; sy, Stiu; su $\ddagger$, Stump; sw, Sundew; sc †, Survey Creek; te, Tlell Estuary; vc $\$$, Vaccinium; vn, Van Inlet; wa $\$$, Watt; we $\$$, Wegner; wh, White Swan; wi, Wiggins; wo, Woodpile; wr, Wright; y, Yakoun; yr, Yakoun River. 